\title{
$\mathrm{Al}, \mathrm{V}, \mathrm{Cr}, \mathrm{Mn}, \mathrm{Ni}, \mathrm{Nb}, \mathrm{Mo}$ 및 $\mathrm{W}$ 첨가에 따른 바이오매스 보일러용 $\mathrm{BCC}-\mathrm{Fe}$ 의 탄성 특성과 경도 변화의 이론적 고찰 \\ 김지웅 ${ }^{1,2} \cdot$ 김명재 $^{1,3} \cdot$ 서창열 $^{1} \cdot$ 류정호 $^{4} \cdot$ 류태공 $^{1} \cdot$ 홍혜진 $^{1,2} \cdot$ 신도연 $^{1,2} \cdot$ 서용재 $^{1,2, *}$ \\ 1 한국지질자원연구원 광물자원연구본부 \\ 2과학기술연합대학원대학교 자원순환공학전공 \\ 3 인하대학교 신소재공학과 \\ 4지질환경연구본부 지질환경재해연구센터
}

\section{Effects of Al, V, Cr, Mn, Ni, Nb, Mo, and W Addition to BCC-Fe on its Elastic Properties and Hardness for a Biomass Boiler: First Principles Approaches}

\author{
Jiwoong Kim ${ }^{1,2}$, MyungJae Kim ${ }^{1,3}$, Chang Yul Seo ${ }^{1}$, Jungho Ryu ${ }^{4}$, Taegong Ryu ${ }^{1}$, \\ Hye-Jin Hong, ${ }^{1,2}$, Doyeon Shin ${ }^{1,2}$, and Yong Jae Suh ${ }^{1,2, *}$ \\ ${ }^{1}$ Korea Institute of Geoscience and Mineral Resources, Mineral Resources Research Division, Daejeon 34132, Republic of Korea
${ }^{2}$ Division of Resources Recycling, Korea University of Science and Technology, Daejeon 34113, Republic of Korea
${ }^{3}$ Materials Science and Engineering, Inha University, Incheon 22212, Republic of Korea
${ }^{4}$ Geologic Environment Research Division, Korea Institute of Geoscience and Mineral Resources, Daejeon 34132, Republic of Korea
}

\begin{abstract}
During biomass combustion for renewable energy generation, combustion byproducts such as fly ash and metal chlorides cause serious erosion problems in boilers, as well as corrosion. To develop a highly wear-resistant composition of alloy for biomass boilers, we investigated how the addition of various metallic elements to BCC-Fe affected its elastic properties using first principles calculations. The added elements were $\mathrm{Al}, \mathrm{V}, \mathrm{Cr}, \mathrm{Mn}, \mathrm{Ni}, \mathrm{Nb}, \mathrm{Mo}$, and W. These elements used to be included in T91 and T92 steels, which are considered suitable materials for biomass boilers. Our results revealed that except for $\mathrm{Al}$ and $\mathrm{Ni}$, all of the other elements increased shear and Young's moduli, implying high wear-resistant characteristics. In contrast, all of the added elements decreased bulk modulus. Furthermore, V, Cr, Nb, Mo, and W increased atomic bonding strength and thus the escape energy of Fe atoms, leading to hindrance of corrosion by metal chlorides, too. To design a highly wear-resistant BCC-Fe alloy for biomass boilers, the additive elements and their amounts are important, in the order of $\mathrm{Mn}, \mathrm{Cr}, \mathrm{Mo}, \mathrm{W}>\mathrm{V}, \mathrm{Nb}>>\mathrm{Al}$, Ni. We expect that the present results will provide a basic guideline when developing Fe-based materials with superior elastic and mechanical properties for biomass renewable energy generation.
\end{abstract}

(Received December 4, 2018; Accepted May 2, 2019)

Keywords: biomass boiler, new and renewable energy, iron erosion, theoretical calculation, elastic property, BCC-Fe alloy

\section{1. 서 론}

바이오매스(biomass) 신재생 발전은 기존의 화력발전소 에 설치된 보일러를 그대로 사용하고 다른 에너지원들에

- 김지웅 · 서창열 · 류정호 · 류태공 · 홍혜진 · 신도연 · 서용재: 연구원, 김명재: 박사과정

${ }^{*}$ Corresponding Author: Yong Jae Suh

[Tel: +82-42-868-3570, E-mail: aumsuh@kigam.re.kr]

Copyright (c) The Korean Institute of Metals and Materials
비해 저장 및 취급 시설에 대한 투자비용이 훨씬 적어 경 제적이며 현실적인 신재생에너지이다. 이러한 장점에 힘입 어 유럽에서는 1000 개 이상의 바이오매스 신재생 발전소 가 운행되고 있으며 앞으로도 그 숫자는 더욱 증가할 전망 이다 [1]. 여러 바이오매스 중 신재생 발전에 주로 사용되 고 있는 목질펠릿(wood pellet)은 난방 및 발전 부분에 사 용되는 연료자원으로 분류되어 국제표준규격(ISO)에 의거 하여 관리·유통되고 있다. 바이오매스 신재생 에너지에 대 한 관심과 수요는 계속 증가할 것으로 예상되며 이에 따른 
목질펠릿의 수요 역시 꾸준히 증가할 것으로 예상된다 [2]. 바이오매스는 기존의 화력발전소에서 사용되던 보일러로 발전할 수 있다는 장점이 있지만 보일러에 심각한 부식을 유발한다. 왜냐하면 바이오매스 연소 시 강한 부식성 염화 물인 $\mathrm{KCl}, \mathrm{NaCl}$ 등의 부가 물질이 생성되기 때문이다. 그 결과 바이오매스 보일러 내부에서는 고온 부식뿐만 아니라 염소와 염화물로 인한 부식이 심각하게 발생하여 바이오매 스 신재생 발전에 걸림돌이 되고 있다 $[3,4] . \mathrm{Cl}$ 은 금속 산 화층을 침투하여 융점이 낮은 $\mathrm{FeCl}_{2}$ 를 형성한 후 고온에서 기화되어 보일러 내부를 심각하게 부식시킨다.

염화물에 의한 부식 이외에 또 다른 심각한 문제는 재침 식(ash-erosion)이다. 재침식이란 바이오매스 연소 시 발생 하는 비산재(fly ash)가 전열관에 장착된 클링커(clinker)를 제거하기 위해 공급되는 고온 증기에 실려 고속으로 유동 하면서 보일러 배관 표면을 마모시키는 침식 현상이다. 재 침식을 줄이기 위한 가스 유속 적정화, 가스 편류 방지, 프로텍터 설치 등의 대책에도 불구하고 재침식은 부식과는 달리 단시간에 설비를 파괴할 수 있는 위력이 있어 염화물 에 의한 부식보다 더 심각한 문제이다 [5,6]. 그러므로 바 이오매스 보일러 내부 설비는 높은 내부식성뿐만 아니라 높은 내마모성도 갖추고 있어야 한다.

내부식-내마모성이 향상된 보일러용 내벽 소재 및 코팅 재를 개발하기 위하여 이 논문에서는 $\mathrm{Fe}$ 소재의 내부식성 을 향상시키는 것으로 알려진 8 가지 원소들이 $\alpha-\mathrm{Fe}$ 의 물 리적 강도와 경도에 미치는 영향을 제1원리 계산으로 연 구하였다. $\mathrm{Fe}$ 소재의 특성을 향상시키기 위해 일반적으로 첨가하는 원소의 양과 이 연구에서 사용한 $\mathrm{BCC}-\mathrm{Fe}$ 모델 의 원자 개수를 고려하여 $\mathrm{Al}, \mathrm{V}, \mathrm{Cr}, \mathrm{Mn}, \mathrm{Ni}, \mathrm{Nb}, \mathrm{Mo}$, $\mathrm{W}$ 을 각각 6.25 (1/16), 12.5 (1/8) at $\%$ 첨가한 모델을 만 들어 금속 원소 첨가 시 $\alpha-\mathrm{Fe}$ 의 내마모 특성에 미치는 영 향을 분석하였다. 이 논문이 내부식성과 내마모성을 모두 갖춘 바이오매스 보일러 소재 개발에 가이드 라인을 제시 할 수 있을 것이라 기대한다.

\section{2. 계산 방법}

이 논문에서는 $\mathrm{BCC}-\mathrm{Fe}$ 에 내부식성 금속 원소 $\mathrm{Al}, \mathrm{V}$, $\mathrm{Cr}, \mathrm{Mn}, \mathrm{Ni}, \mathrm{Nb}, \mathrm{Mo}, \mathrm{W}$ 을 각각 $1 / 16$ 및 $1 / 8$ 첨가 시 물리적 강도와 경도의 변화를 살펴보았다. 이를 위해 전자 밀도 이론(density functional theory)을 기반으로 한 제1원 리 계산을 수행하였으며 [7,8] 상용 코드인 Vinnea Ab initio Simulation Package (VASP)를 사용하였다 [9-11]. Exchangecorrelation 에너지는 generalized gradient approximation

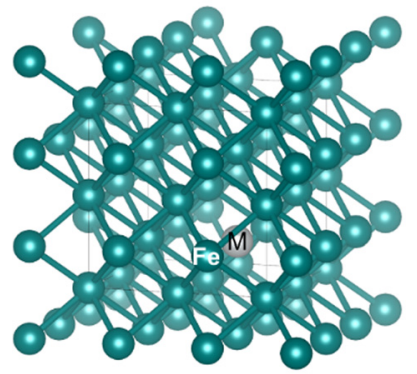

(a) $\mathrm{Fe}_{0.9375} \mathrm{M}_{0.0625}$

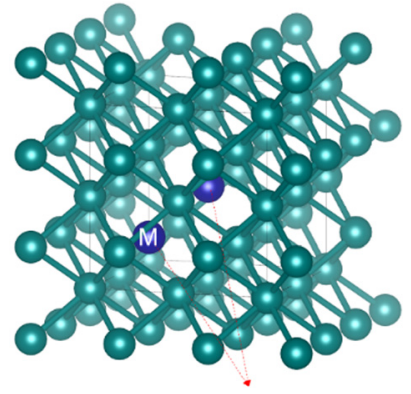

Random substitution

(b) $\mathrm{Fe}_{0.875} \mathrm{M}_{0.125}$

Fig. 1. Model structures of BCC-Fe based alloys.

with the Perdew-Burke-Ernzerhof parameterization을 이용 하였다 [12]. 강자성체(ferromagnetic)인 $\mathrm{BCC}-\mathrm{Fe}$ 의 특성을 고려하여 spin-polarized 계산을 사용하였으며, 높은 plane-wave cutoff energy $(500 \mathrm{eV})$ 를 설정하여 계산의 정 확도를 향상시켰다.

BCC-Fe 구조 내 8종의 금속 원소를 무작위로 치환한다는 가정하에 $1 / 16$ 모델의 경우 $2 \times 2 \times 2$ BCC-Fe supercell 정 중앙에 위치한 $\mathrm{Fe}$ 원자 하나를 다른 종의 금속 원소로 치 환하였다(그림 1a). $\mathrm{Fe} 2$ 개가 치환된 $1 / 8$ 모델의 경우 $\mathrm{BCC}-\mathrm{Fe}$ supercell 내 전체 16 개 $\mathrm{Fe}$ 원자 중 2개를 무작 위로 치환한 모델을 5 개 생성하여 탄성 특성과 경도를 계 산한 후 이들의 평균값을 결과로 산출하였다(그림 1b). 모 델을 생성한 이후 각각의 모델에 구조최적화를 수행하였다. Brillouin zone 적분 시 Monkhorst k-points pack grid를 사용하였으며, 최적의 k-points grid size를 얻기 위하여 $\mathrm{Fe}_{15} \mathrm{M}_{1}$ supercell로 k-point 수렴 테스트를 수행하였다(그림 2). Total electronic energy를 계산할 때는 coarse size kpoints grid에서도 수렴하였으나 격자 상수(lattice parameter) 계산 시에는 precise k-points mesh size에서 수렴하였다. 따라서 이 논문에서는 $5 \times 5 \times 5$ Monkhorst pack grid를 사용하여 구조를 최적화하고 탄성 특성을 계산하였다.

생성열(heat of formation)과 응집에너지(cohesive energy) 를 얻기 위하여 각 금속 원소의 stable state energy (SSE) 와 atomic state energy (ASE)를 계산하였다. SSE와 ASE 는 상온에서 각 원소가 이루는 안정한 결정 구조가 갖는 에너지와 각 원소가 독립된 원자 상태로 존재할 때의 total electronic energy를 의미한다. SSE 계산 시 구조의 크기 와 k-points 수렴을 고려하여 $15 \times 15 \times 15$ Monkhorst pack grid에 구조 최적화 과정에서 적용하였던 세팅을 동 일하게 사용하였다. ASE 계산 시에는 $12 \times 12 \times 12 \AA$ 크 기 정사각형 격자의 원점에 각 원자 하나를 놓고 gamma 


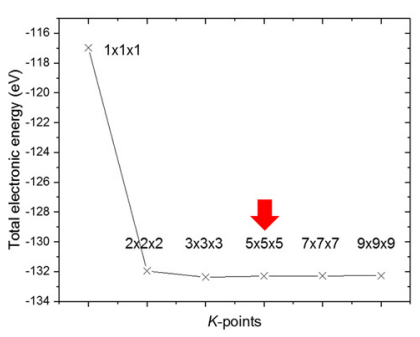

(a) Total electronic energy

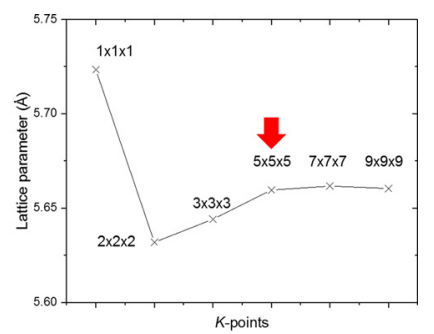

(b) Lattice parameter
Fig. 2. Results of K-points convergence tests for $\mathrm{Fe}_{0.9375} \mathrm{Mn}_{0.0625}$ alloy.

k-point로 에너지를 계산하였다.

이종 원소가 첨가된 $\mathrm{BCC}-\mathrm{Fe}$ 의 탄성 특성을 계산하기 위하 여 strain-stress relation을 도입하였다 [13,14]. Fe16 supercell 모델에 이종의 원소를 첨가할 경우 최적화된 구조가 엄밀 한 의미의 입방(cubic) 구조는 아니지만 입방 특성을 갖고 있으므로 입방정계로 가정하고 계산하더라도 큰 오차를 보 이지 않는다. 이 논문에서는 모든 모델을 입방 구조로 가 정하여 3 개의 입방 탄성 상수 $\left(\mathrm{C}_{11}, \mathrm{C}_{12}\right.$, and $\left.\mathrm{C}_{44}\right)$ 를 계산 하였다. 탄성 상수를 얻기 위하여 최적화된 구조의 모델에 각각 두 방향으로 4 개의 변형률 $( \pm 0.005, \pm 0.007)$ 을 적용 하였다. 또한 Voight-Reuss-Hill 가정에 따라 탄성 상수 값 으로부터 다결정 탄성 특성을 식 (1) (3)을 이용하여 계산 하였다 [13-16].

$$
\begin{aligned}
& \mathrm{G}=\frac{3 \mathrm{C}_{44}+\mathrm{C}_{11}-\mathrm{C}_{12}}{5}, \\
& \mathrm{E}=\frac{9 \mathrm{~GB}}{3 \mathrm{~B}+\mathrm{G}}, \\
& \mathrm{B}=\frac{\mathrm{C}_{11}+2 \mathrm{C}_{12}}{3},
\end{aligned}
$$

위 식에서 $G$ 는 전단 탄성계수(shear modulus), $E$ 는 영 률(Young's modulus), $B$ 는 부피 탄성계수(bulk modulus) 를 의미한다.

\section{3. 결과 및 고찰}

3.1. $\mathrm{Al}, \mathrm{V}, \mathrm{Cr}, \mathrm{Mn}, \mathrm{Ni}, \mathrm{Nb}, \mathrm{Mo}, \mathrm{W}$ 첨가에 따

\section{른 $\mathrm{BCC}-\mathrm{Fe}$ 구조의 변화}

탄성 특성을 계산하기에 앞서 $\mathrm{Al}, \mathrm{V}, \mathrm{Cr}, \mathrm{Mn}, \mathrm{Ni}, \mathrm{Nb}$, $\mathrm{Mo}, \mathrm{W}$ 을 $\mathrm{BCC}-\mathrm{Fe}$ 에 첨가하였을 때 발생하는 격자 상수의 변화를 먼저 살펴보았다(그림 3). 순수 BCC-Fe $2 \times 2 \times$ 2 supercell의 격자 상수는 $\sim 5.66 \AA$ (unit cell: $\sim 2.83 \AA$ )으 로 계산되었으며, 이 값은 실험치와 잘 일치하였다 [17].

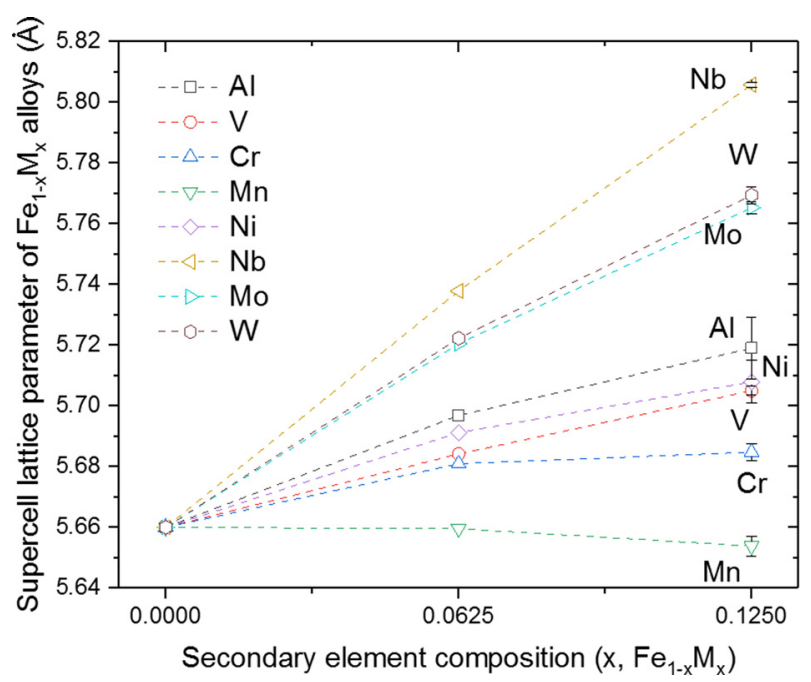

Fig. 3. Effects of addition of the metallic elements on lattice parameter of BCC-Fe.

$\mathrm{Mn}$ 을 제외한 나머지 원소들의 경우 모두 격자 상수가 증 가하였다. $\mathrm{Mn}$ 은 첨가량이 증가함에 따라 격자 상수가 감 소하는 경향을 나타내었으며 나머지 7종의 원소들은 첨가 량에 따라 격자 상수가 거의 선형적으로 비례 증가하였다. 원자 크기 측면에서 $\mathrm{Nb}, \mathrm{Mo}, \mathrm{W}$ 은 $\mathrm{Fe}$ 보다 더 크기 때문 에 격자 상수 증가가 예상된 반면, $\mathrm{Al}$ 과 $\mathrm{Ni}$ 의 경우 격자 상수가 감소하리라는 예상과 달리 오히려 증가하였다. 이 때 격자 상수의 증가는 원자 간 결합 거리의 증가에 기인 한 것으로 여겨진다. 결합 거리의 변화는 탄성 특성에 직 접 영향을 미치는 주요 인자이다. 격자 상수가 변화해 가 는 경향으로 미루어 볼 때 $\mathrm{BCC}-\mathrm{Fe}$ 내 $\mathrm{Nb}, \mathrm{Mo}, \mathrm{W}$ 등 의 원소 비율이 높아질수록 순수 $\mathrm{BCC}-\mathrm{Fe}$ 와의 격자 상수 차이가 증가할 가능성이 높으며 이는 격자 불일치(lattice mismatch)로 이어질 수 있다.

3.2. $\mathrm{Al}, \mathrm{V}, \mathrm{Cr}, \mathrm{Mn}, \mathrm{Ni}, \mathrm{Nb}, \mathrm{Mo}, \mathrm{W}$ 첨가에 따 른 $\mathrm{BCC}-\mathrm{Fe}$ 의 생성열 및 응집에너지 변화

이종 원소의 첨가에 따른 열역학적 안정성과 물질 결합 력의 변화는 합금 조성 평가 시 중요한 지표로 쓰인다. 먼 저 합금의 열역학적 안정성을 평가하기 위하여 각 $\mathrm{Fe}_{1-\mathrm{x}} \mathrm{M}_{\mathrm{x}}$ 합금의 생성열을 계산하였다. 생성열을 계산하기 위해서는 상온에서 안정한 구조를 이루고 있는 금속 원소의 에너지 (SSE)가 필요하며, 합금의 결합력과 순수한 금속 원소의 결합력 차이를 계산하기 위해서는 원자들의 에너지(ASE) 역시 필요하다. 이 논문에서 사용된 8 종의 합금 원소와 $\mathrm{Fe}$ 의 $\mathrm{SSE}$ 와 $\mathrm{ASE}$ 계산 결과를 표 1 에 나타내었다.

표 1 의 $\mathrm{SSE}$ 와 $\mathrm{ASE}$ 값과 각 합금의 total electronic 
Table 1. Stable and atomic state energies of $\mathrm{Al}, \mathrm{V}, \mathrm{Cr}, \mathrm{Mn}, \mathrm{Ni}, \mathrm{Nb}, \mathrm{Mo}, \mathrm{W}$, and $\mathrm{Fe}$

\begin{tabular}{cccccc}
\hline Element & $\begin{array}{c}\text { Stable state } \\
\text { crystal structure }\end{array}$ & Space group & Lattice parameter $[\AA]$ & SSE [eV] & ASE [eV] \\
\hline $\mathrm{Al}$ & $\mathrm{FCC}$ & Fm-3m & 4.035 & -3.746 & -0.226 \\
\hline $\mathrm{V}$ & $\mathrm{BCC}$ & $\mathrm{Im}-3 \mathrm{~m}$ & 2.994 & -8.994 & -3.590 \\
\hline $\mathrm{Cr}$ & $\mathrm{BCC}$ & $\mathrm{Im}-3 \mathrm{~m}$ & 2.845 & -9.514 & -1.204 \\
\hline $\mathrm{Mn}$ & $\mathrm{BCC}$ & $\mathrm{Im}-3 \mathrm{~m}$ & 2.795 & -8.852 & -5.145 \\
\hline $\mathrm{Ni}$ & $\mathrm{FCC}$ & $\mathrm{Fm}-3 \mathrm{~m}$ & 3.518 & -5.467 & -0.308 \\
\hline $\mathrm{Nb}$ & $\mathrm{BCC}$ & $\mathrm{Im}-3 \mathrm{~m}$ & 3.309 & -10.214 & -3.224 \\
\hline $\mathrm{Mo}$ & $\mathrm{BCC}$ & $\mathrm{Im}-3 \mathrm{~m}$ & 3.164 & -10.932 & -4.636 \\
\hline $\mathrm{W}$ & $\mathrm{BCC}$ & $\mathrm{Im}-3 \mathrm{~m}$ & 3.186 & -12.953 & -4.560 \\
\hline $\mathrm{Fe}$ & $\mathrm{BCC}$ & $\mathrm{Im}-3 \mathrm{~m}$ & 2.830 & -8.237 & -3.120 \\
\hline
\end{tabular}

Table 2. Effects of addition of the elements on heat of formation and cohesive energy of BCC-Fe

\begin{tabular}{ccc}
\hline $\begin{array}{c}\text { Chemical } \\
\text { formula }\end{array}$ & $\begin{array}{c}\text { Heat of formation } \\
{[\mathrm{kJ} / \mathrm{mol}]}\end{array}$ & $\begin{array}{c}\text { Cohesive energy } \\
\text { difference [eV/atom] }\end{array}$ \\
\hline $\mathrm{Fe}_{0.9375} \mathrm{Al}_{0.0625}$ & -4.368 & 0.055 \\
\hline $\mathrm{Fe}_{0.875} \mathrm{Al}_{0.125}$ & -8.165 & 0.115 \\
\hline $\mathrm{Fe}_{0.9375} \mathrm{~V}_{0.0625}$ & -4.269 & -0.062 \\
\hline $\mathrm{Fe}_{0.875} \mathrm{~V}_{0.125}$ & -6.181 & -0.999 \\
\hline $\mathrm{Fe}_{0.9375} \mathrm{Cr}_{0.0625}$ & -0.478 & -0.205 \\
\hline $\mathrm{Fe}_{0.875} \mathrm{Cr}_{0.125}$ & 0.536 & -0.394 \\
\hline $\mathrm{Fe}_{0.9375} \mathrm{Mn}_{0.0625}$ & 0.690 & 0.095 \\
\hline $\mathrm{Fe}_{0.875} \mathrm{Mn}_{0.125}$ & 1.392 & 0.191 \\
\hline $\mathrm{Fe}_{0.9375} \mathrm{Ni}_{0.0625}$ & 0.167 & -0.001 \\
\hline $\mathrm{Fe}_{0.875} \mathrm{Ni}_{0.125}$ & 0.815 & 0.003 \\
\hline $\mathrm{Fe}_{0.9375} \mathrm{Nb}_{0.0625}$ & -1.222 & -0.130 \\
\hline $\mathrm{Fe}_{0.875} \mathrm{Nb}_{0.125}$ & -0.070 & -0.235 \\
\hline $\mathrm{Fe}_{0.9375} \mathrm{Mo}_{0.0625}$ & 0.321 & -0.070 \\
\hline $\mathrm{Fe}_{0.875} \mathrm{Mo}_{0.125}$ & 2.247 & -0.124 \\
\hline $\mathrm{Fe}_{0.9375} \mathrm{~W}_{0.0625}$ & -0.158 & -0.206 \\
\hline $\mathrm{Fe}_{0.875} \mathrm{~W}_{0.125}$ & 1.465 & -0.394 \\
\hline $\mathrm{BCC} \mathrm{Fe}$ & 0.000 & 0.000 \\
\hline
\end{tabular}

energy로부터 $\mathrm{Fe}_{1-\mathrm{x}} \mathrm{M}_{\mathrm{x}}$ 합금의 생성열과 응집에너지를 계산 하였다(표 2) [18]. 합금의 생성열이 양의 값을 가질 때 그 합금은 불안정한 상이다. $\mathrm{Al}$ 과 $\mathrm{V}$ 은 그 첨가량이 증가 함에 따라 $\mathrm{Fe}$ 의 상 안정에 도움을 주고 있으므로 $\mathrm{BCC}-\mathrm{Fe}$ 내 많은 양의 $\mathrm{Al}$ 과 $\mathrm{V}$ 을 첨가해도 안정한 합금을 형성하게 된다. $\mathrm{Cr}, \mathrm{Nb}, \mathrm{W}$ 등은 $6.25 \mathrm{at} \%$ 첨가하였을 경우 안정 한 상을 이루지만 첨가량이 $12.5 \mathrm{at} \%$ 로 증가하면 생성열 이 0 에 가까워지거나 양의 값을 가져 불안정한 합금을 만 든다. 즉, $\mathrm{Cr}, \mathrm{Nb}, \mathrm{W}$ 은 소량의 분율이 첨가된 합금만 제 조 가능하다. 나머지 원소 $\mathrm{Mn}, \mathrm{Ni}, \mathrm{Mo}$ 은 소량 첨가에도
불안정한 합금을 이루므로 활성화 에너지 이상의 에너지 상태에서 원소 분리가 일어날 수 있다. 그러나 실제 T91, $\mathrm{T} 92$ 등의 합금에서 이러한 원소 분리 현상은 일어나지 않 는데, 이는 이 논문에서 엔트로피에 대한 영향을 고려하지 않았기 때문이다. 합금을 형성하는 높은 온도에서는 엔트 로피에 의한 안정화 효과가 커져 합금을 형성할 수 있다.

이종 원소를 $\mathrm{BCC}-\mathrm{Fe}$ 에 첨가하였을 때 결합력의 변화를 알 아보기 위하여 응집에너지 차이를 식 (4)와 같이 계산하였다.

$$
E^{\text {coh,diff }}=E^{\text {coh,alloy }}-E^{\text {coh,BCC-Fe }}
$$

식 (4)에서 $\mathrm{E}^{\mathrm{coh}, \mathrm{diff}}, \mathrm{E}^{\mathrm{coh} \text {,alloy }}, \mathrm{E}^{\mathrm{coh}, \mathrm{BCC}-\mathrm{Fe}}$ 는 각각 순수 $\mathrm{BCC}-\mathrm{Fe}$ 과 합금의 응집에너지 차이, 합금의 응집에너지, 순 수 $\mathrm{BCC}-\mathrm{Fe}$ 합금의 응집에너지를 의미한다. $\mathrm{V}, \mathrm{Cr}, \mathrm{Nb}$, $\mathrm{Mo}, \mathrm{W}$ 등을 첨가할 경우 순수 $\mathrm{BCC}-\mathrm{Fe}$ 보다 결합력이 더 커졌다. $\mathrm{Al}$ 과 $\mathrm{Mn}$ 첨가 시 원자 간 결합력이 약해졌으며, $\mathrm{Ni}$ 첨가 시에는 결합력에 변화가 거의 없었다. 원자 간 결 합력이 증가하면 $\mathrm{BCC}-\mathrm{Fe}$ 표면에서 $\mathrm{Fe}$ 원자의 이탈에너지 (escape energy)가 증가하므로 염소에 의한 부식 현상을 감소시킬 수 있다.

\section{3. $\mathrm{Al}, \mathrm{V}, \mathrm{Cr}, \mathrm{Mn}, \mathrm{Ni}, \mathrm{Nb}, \mathrm{Mo}, \mathrm{W}$ 첨가에 따} 른 $\mathrm{BCC}-\mathrm{Fe}$ 탄성 특성의 변화

Strain-stress relation을 도입하여 합금의 탄성 상수 (elastic constant)를 계산하였다(표 3). 순수 BCC-Fe에 이 종의 금속 원소가 첨가될 경우 입방 대칭성이 다소 깨지는 경향이 있지만 이 논문에서는 cubic relation을 이용하였다 [15]. 표 3에 나타낸 바와 같이 대부분의 원소가 첨가됨에 따라 입방 탄성 상수 $\mathrm{C}_{11}$ 과 $\mathrm{C}_{12}$ 는 다소 줄어드는 경향을 보였다. 반면, $\mathrm{C}_{44}$ 비틀림 탄성 상수는 $\mathrm{Nb}$ 을 제외한 나머 지 합금 원소 첨가 시 모두 상승하였으며, $\mathrm{Al}, \mathrm{V}, \mathrm{Ni}$ 은 
Table 3. Cubic elastic constants of $\mathrm{Fe}_{1-\mathrm{x}} \mathrm{M}_{\mathrm{x}}$ alloys $(\mathrm{x}=0.0625$ and $0.125)$

\begin{tabular}{cccc}
\hline $\begin{array}{c}\text { Chemical } \\
\text { formula }\end{array}$ & $\mathrm{C}_{11}[\mathrm{GPa}]$ & $\mathrm{C}_{12}[\mathrm{GPa}]$ & $\mathrm{C}_{44}[\mathrm{GPa}]$ \\
\hline $\mathrm{Fe}_{0.9375} \mathrm{Al}_{0.0625}$ & 233.8 & 153.2 & 121.16 \\
\hline $\mathrm{Fe}_{0.875} \mathrm{Al}_{0.125}$ & 175.2 & 93.5 & 109.9 \\
\hline $\mathrm{Fe}_{0.9375} \mathrm{~V}_{0.0625}$ & 244.7 & 136.2 & 101.3 \\
\hline $\mathrm{Fe}_{0.875} \mathrm{~V}_{0.125}$ & 251.8 & 135.9 & 97.1 \\
\hline $\mathrm{Fe}_{0.9375} \mathrm{Cr}_{0.0625}$ & 229.1 & 109.1 & 88.1 \\
\hline $\mathrm{Fe}_{0.875} \mathrm{Cr}_{0.125}$ & 273.5 & 137.3 & 128.2 \\
\hline $\mathrm{Fe}_{0.9375} \mathrm{Mn}_{0.0625}$ & 248.2 & 122.9 & 107.3 \\
\hline $\mathrm{Fe}_{0.875} \mathrm{Mn}_{0.125}$ & 281.1 & 152.5 & 115.9 \\
\hline $\mathrm{Fe}_{0.9375} \mathrm{Ni}_{0.0625}$ & 248.5 & 141.2 & 105.3 \\
\hline $\mathrm{Fe}_{0.875} \mathrm{Ni}_{0.125}$ & 189.5 & 131.2 & 90.5 \\
\hline $\mathrm{Fe}_{0.9375} \mathrm{Nb}_{0.0625}$ & 240.1 & 133.2 & 92.1 \\
\hline $\mathrm{Fe}_{0.875} \mathrm{Nb}_{0.125}$ & 248.1 & 148.8 & 98.7 \\
\hline $\mathrm{Fe}_{0.9375} \mathrm{Mo}_{0.0625}$ & 227.4 & 109.8 & 94.7 \\
\hline $\mathrm{Fe}_{0.875} \mathrm{Mo}_{0.125}$ & 280.13 & 150.2 & 112.1 \\
\hline $\mathrm{Fe}_{0.9375} \mathrm{~W}_{0.0625}$ & 241.0 & 128.1 & 95.3 \\
\hline $\mathrm{Fe}_{0.875} \mathrm{~W}_{0.125}$ & 290.2 & 172.7 & 126.7 \\
\hline $\mathrm{BCC} \mathrm{Fe}$ & 260.3 & 168.7 & 95.3 \\
\hline
\end{tabular}

첨가량이 증가함에 따라 다시 감소하는 경향을 보였다. 이 결과는 적은 양의 $\mathrm{Al}, \mathrm{V}, \mathrm{Ni}$ 을 첨가하면 경도를 증가시킬 수 있지만 일정수준 이상 첨가할 경우 오히려 경도를 감소시켜 내마모성을 약화시킬 수 있음을 의미한다. 이러한 탄성 상수 값으로부터 식 (1), (2)를 사용하여 내마모성을 평가할 수 있 는 전단 탄성계수와 영률을 계산하였다(그림 $4 \mathrm{a}, 4 \mathrm{~b}$ ).

내마모성을 직접 평가할 수 있는 전단 탄성계수와 영률 은 소량의 원소 첨가 시 모든 원소에서 비슷한 수준으로 향상되었으며, $\mathrm{Al}$ 과 $\mathrm{Ni}$ 을 제외한 나머지 원소들의 경우에 는 첨가량이 증가함에 따라 상승하였다. $\mathrm{Ni}$ 을 $\mathrm{BCC}-\mathrm{Fe}$ 에 소량 첨가하면 전단 탄성계수와 영률을 증가시킬 수 있지 만 $12.5 \mathrm{at} \%$ 이상 첨가하면 내마모성에 심각한 저하를 초 래할 수 있으므로 각별한 주의가 필요하다.

한편, 이종 원소 첨가 시 모든 원소에서 부피 탄성계수 가 감소하였다. $\mathrm{Cr}, \mathrm{Mn}, \mathrm{Nb}, \mathrm{Mo}, \mathrm{W}$ 의 경우에는 첨가량 이 증가함에 따라 부피 탄성계수가 다시 상승하는 것을 볼 수 있는데 이는 첨가 원소 본연의 부피 탄성계수 발현에 기인한다. 이는 첨가량이 증가함에 따라 부피 탄성계수가 더욱 떨어지는 $\mathrm{Al}, \mathrm{Ni}$ 과 대조적이나, $\mathrm{Al}$ 과 $\mathrm{Ni}$ 원소 자체

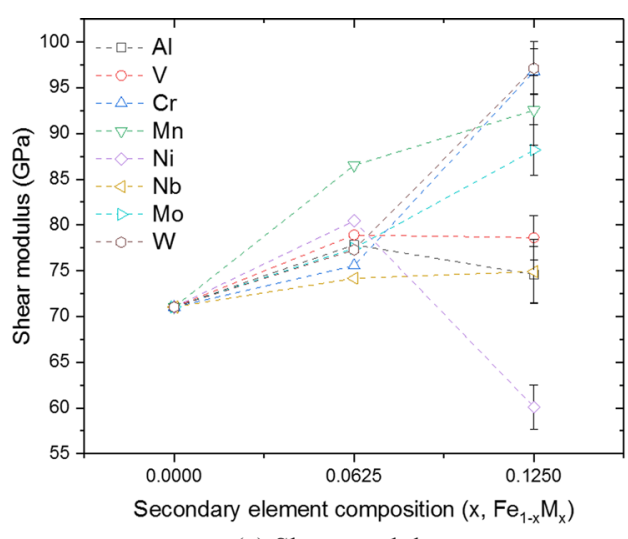

(a) Shear modulus

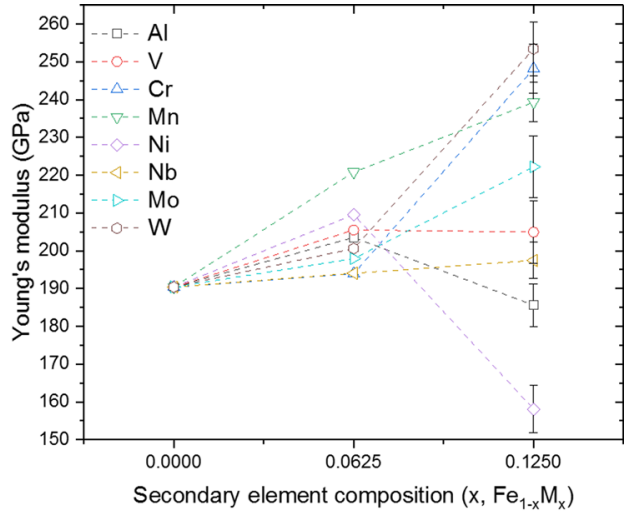

(b) Young's modulus

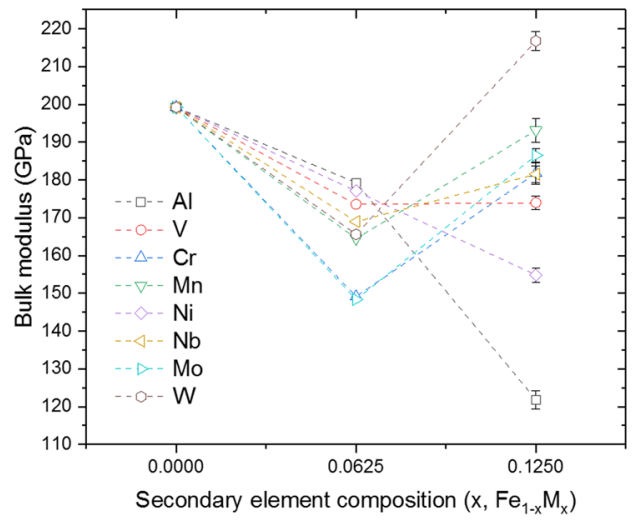

(c) Bulk modulus

Fig. 4. Effects of addition of the metallic elements on elastic moduli of BCC-Fe. 


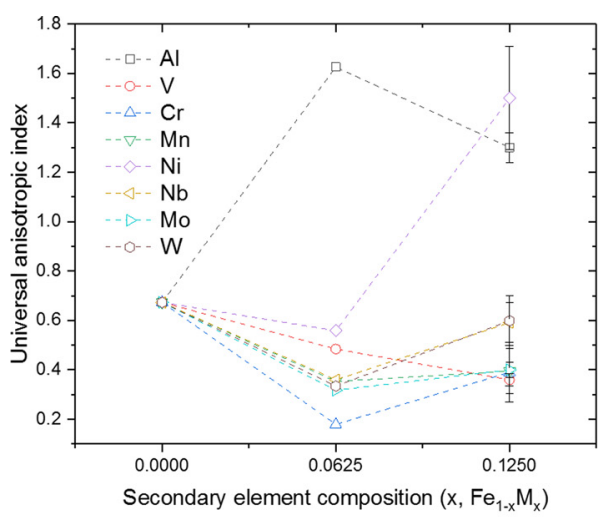

(a) Universal anisotropic index

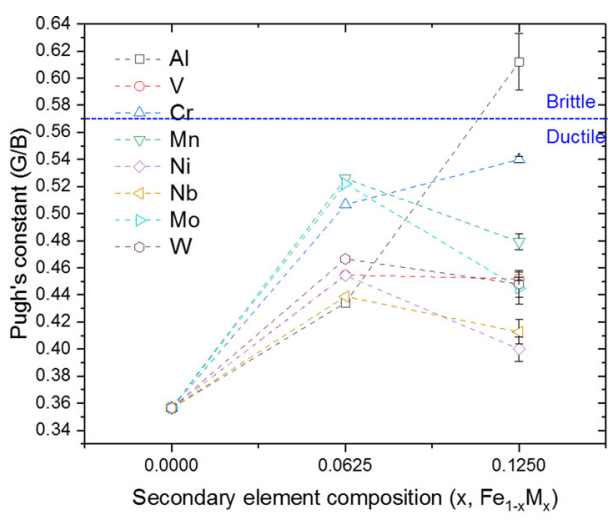

(b) Pugh's constant

Fig. 5. Effects of addition of the metallic elements on anisotropy and brittleness of BCC-Fe.

의 부피 탄성계수가 $\mathrm{Fe}$ 보다 낮으므로 동일한 메커니즘으 로 설명할 수 있다.

마지막으로 이종 원소 첨가가 $\mathrm{BCC}-\mathrm{Fe}$ 의 이방성과 취성 에 미치는 영향을 평가하기 위하여 universal anisotropy index (UAI)와 Pugh's constant를 계산하였다(그림 5)[19, 20]. 원소 첨가에 따른 $\mathrm{BCC}-\mathrm{Fe}$ 의 UAI 변화를 살펴보면(그 림 $5 \mathrm{a}), \mathrm{Al}$ 을 제외한 나머지 원소들은 $6.25 \mathrm{at} \%$ 첨가 시 이방성이 줄어들었다. 첨가량이 $12.5 \mathrm{at} \%$ 로 증가하면 대체 로 이방성이 조금씩 증가하는 경향이 보이지만 순수 BCC$\mathrm{Fe}$ 보다 낮은 수준이었다. 그러나 $\mathrm{Al}$ 의 경우 낮은 함량에도 이방성이 크게 증가하였으며, $\mathrm{Ni}$ 은 $12.5 \mathrm{at} \%$ 첨가 시 $\mathrm{Al}$ 과 마찬가지로 이방성이 크게 증가하였다. 또한 원소 첨가에 따른 BCC-Fe의 취성 변화를 살펴보면(그림 $5 \mathrm{~b}$ ), 모든 원소 에서 취성이 증가하는 경향을 보였다. 특히, $\mathrm{Al}$ 은 $12.5 \mathrm{at} \%$ 첨가 시 취성이 굉장히 크게 증가하여 Pugh's criteria $(G /$ $B>0.57$ )에 따르면 연성 물질에서 취성 물질로 상태가 변 하였다 $[15,18]$. 앞서 언급한 바와 같이 $12.5 \mathrm{at} \%$ 첨가 시 대부분의 원소는 첨가 원소 본연의 높은 부피 탄성계수에 기인하여 취성이 감소하였다. 이때 부피 탄성계수의 상승률 이 전단 탄성계수의 변화율보다 크기 때문에 대부분의 원 소 첨가 시 전체적인 취성은 감소하게 된다. 그러나 $\mathrm{Cr}$ 의 경우 높은 전단 탄성계수 상승률로 인하여 취성이 소폭 증 가하였다. 반면, $\mathrm{Al}$ 의 경우 전단 탄성계수의 변화는 크지 않지만 원소 첨가량 증가에 따른 부피 탄성계수의 감소 폭 이 커 취성이 상대적으로 상승하였다.

\section{4. 결 론}

이 논문은 바이오매스 보일러 내부 설비용 $\mathrm{BCC}-\mathrm{Fe}$ 계 합금 소재를 개발하고자 상용 T91, T92 소재에 첨가되는
8종의 금속 원소( $\mathrm{Al}, \mathrm{V}, \mathrm{Cr}, \mathrm{Mn}, \mathrm{Ni}, \mathrm{Nb}, \mathrm{Mo}, \mathrm{W})$ 가 $\mathrm{BCC}-\mathrm{Fe}$ 의 구조 및 탄성 특성에 미치는 영향을 제 1 원리 계산법으로 연구하였다. $\mathrm{Mn}$ 을 제외한 나머지 원소의 첨 가는 모두 격자 상수를 증가시켰으며 이는 단순히 첨가 원소의 크기뿐만 아니라 원소 간 결합 거리 변화 등 화 학적인 요소도 그 원인으로 작용하였다. $\mathrm{Al}$ 과 $\mathrm{Mn}$ 은 $\mathrm{BCC}-\mathrm{Fe}$ 의 원자 결합력을 떨어뜨리며, $\mathrm{Al}, \mathrm{Mn}, \mathrm{Ni}$ 을 제 외한 나머지 원소들은 원자 결합력을 증가시켰다. $\mathrm{Al}$ 과 $\mathrm{Ni}$ 은 $\mathrm{BCC}-\mathrm{Fe}$ 의 탄성 특성을 저하시키는 경향을 나타내 었으며 나머지 원소들은 부피 탄성계수를 제외한 나머지 전단 탄성계수와 영률에 긍정적인 영향을 미쳤다. 전체적 으로 볼 때 $6.25 \mathrm{at} \%$ 첨가 시에는 상 안정성, 원자 결 합력, 탄성 특성 등에 긍정적인 영향을 줄 수 있으나 그 이상 첨가할 때에는 주의가 필요하다. 결론적으로 $\mathrm{Al}$ 과 $\mathrm{Ni}$ 의 첨가는 $\mathrm{BCC}-\mathrm{Fe}$ 계 합금의 내마모성에 부정적인 영 향을 줄 수 있으므로 첨가 시 첨가량을 신중하게 결정해야 하며, $\mathrm{Mn}, \mathrm{Cr}, \mathrm{Mo}, \mathrm{W}$ 은 $\mathrm{BCC}-\mathrm{Fe}$ 계 합금 내 높은 함량이 포함되어도 내마모성을 향상시킬 것으로 판단된다. $\mathrm{BCC}-$ $\mathrm{Fe}$ 계 합금 조성 개발 시 $\mathrm{Mn}, \mathrm{Cr}, \mathrm{Mo}, \mathrm{W}>\mathrm{V}, \mathrm{Nb}$ $>\mathrm{Al}, \mathrm{Ni}$ 순으로 첨가 원소의 종류와 첨가량을 고려한 다면 내마모성이 우수한 BCC-Fe계 합금 조성을 개발할 수 있을 것으로 기대된다.

\section{감사의 글}

이 논문은 한국전력공사가 재원을 지원한 전력연구원의 2016년 선정 주력연구개발과제 (과제 번호: R16GA15) 및 한국지질자원연구원 주요사업(과제코드: GP2017-011)으로 부터 지원을 받아 수행되었습니다. 


\section{REFERENCES}

1. M. Oksa, P. Auerkari, J. Salonen, and T. Varis, Fuel Process. Technol. 125, 236 (2014).

2. E. Yang, A. Kim, and B. Kim, World Energy Market Insight 17-25, 3 (2017).

3. H. P. Michelsen, F. Frandsen, K. Dam-Johansen, and O. H. Larsen, Fuel Process. Technol. 54, 95 (1998).

4. H. P. Nielsen, F. J. Frandsen, K. Dam-Johansen, and L. L. Baxter, Prog. Energy Combust. Sci. 26, 283 (2000).

5. B.-Q. Wang, Wear 188, 40 (1995).

6. M. M. El Rayes, H. S. Abdo, and K. A. Khalil, Int. J. Electrochem. Sci. 8, 1117 (2013).

7. P. D. Bhuyan, S. K. Gupta, D. Singh, Y. Sonvane, and P. Gajjar, Met. Mater. Int. 24, 904 (2018).

8. B.-J. Lee, Korean J. Met. Mater. 56, 253 (2018).

9. G. Kresse and J. Hafner, Phys. Rev. B: Condens. Matter 49, 14251 (1994).

10. J. Hafner, Comput. Phys. Commun. 177, 6 (2007).
11. J. Hafner, J. Comput. Chem. 29, 2044 (2008).

12. J. P. Perdew, K. Burke, and M. Ernzerhof, Phys. Rev. Lett. 77, 3865 (1996).

13. M. A. Meyers and K. K. Chawla, Mechanical behavior of materials, Cambridge University Press, Cambridge (2009).

14. X.-S. Zhao, S.-L. Shang, Z.-K. Liu, and J.-Y. Shen, J. Nucl. Mater. 415, 13 (2011).

15. J. Kim and S. Kang, J. Alloy. Compd. 528, 20 (2012).

16. J. Kim and Y. J. Suh, J. Alloy. Compd. 666, 262 (2016).

17. J.-W. Hwang, Thermal expansion of nickel and iron, and the influence of nitrogen on the lattice parameter of iron at the Curie temperature, 90, University of Missouri-Rolla (1972).

18. J. Kim, Y. J. Suh, and I. Kang, J. Alloy. Compd. 656, 213 (2016).

19. S. I. Ranganathan and M. Ostoja-Starzewski, Phys. Rev. Lett. 101, 055504 (2008).

20. S. Pough, Philos. Mag. 45, 823 (1954). 